\title{
A Method Based on Intuitionistic Fuzzy Dependent Aggregation Operators for Supplier Selection
}

\author{
Fen Wang, ${ }^{1,2}$ Shouzhen Zeng, ${ }^{3}$ and Chonghui Zhang ${ }^{4}$ \\ ${ }^{1}$ College of Business Administration, Zhejiang Gongshang University, Hangzhou 310018, China \\ ${ }^{2}$ School of Management, Zhejiang Ocean University, Zhoushan 316004, China \\ ${ }^{3}$ College of Computer and Information, Zhejiang Wanli University, Ningbo 315100, China \\ ${ }^{4}$ College of Statistics and Mathematics, Zhejiang Gongshang University, Hangzhou 310018, China \\ Correspondence should be addressed to Shouzhen Zeng; zszzxl@163.com
}

Received 12 July 2013; Accepted 23 September 2013

Academic Editor: Hung Nguyen-Xuan

Copyright (C) 2013 Fen Wang et al. This is an open access article distributed under the Creative Commons Attribution License, which permits unrestricted use, distribution, and reproduction in any medium, provided the original work is properly cited.

\begin{abstract}
Recently, resolving the decision making problem of evaluation and ranking the potential suppliers have become as a key strategic factor for business firms. In this paper, two new intuitionistic fuzzy aggregation operators are developed: dependent intuitionistic fuzzy ordered weighed averaging (DIFOWA) operator and dependent intuitionistic fuzzy hybrid weighed aggregation (DIFHWA) operator. Some of their main properties are studied. A method based on the DIFHWA operator for intuitionistic fuzzy multiple attribute decision making is presented. Finally, an illustrative example concerning supplier selection is given.
\end{abstract}

\section{Introduction}

As extension of Zadeh's fuzzy set [1] whose basic component is only a membership function, Atanassov [2-4] introduced the concept of intuitionistic fuzzy set (IFS). Bustince and Burillo [5] showed that IFS are vague sets [6]. IFS has been proven to be highly useful to deal with uncertainty and vagueness, and a lot of work has been done to develop and enrich the IFS theory $[7,8]$. In many complex decision making problems, the decision information provided by the decision maker is often imprecise or uncertain [9] due to time pressure, lack of data, or the decision maker's limited attention and information processing capabilities. Thus, IFS is a very suitable tool to be used to describe imprecise or uncertain decision information. Recently, some approaches were investigated to multiple attribute decision making (MADM) problems based on intuitionistic fuzzy sets [10-14]. One of the important things of the MADM problems is to aggregate the information provided by the experts. Aggregating intuitionistic fuzzy information has received more and more attention in recent years. Xu and Yager [15] developed some geometric aggregation operators based on intuitionistic fuzzy sets, such as intuitionistic fuzzy weighed geometric (IFWG) operator, intuitionistic fuzzy ordered weighed geometric (IFOWG) operator, intuitionistic fuzzy hybrid geometric (IFHG) operator and applied them to multiple attribute decision making. $\mathrm{Xu}[16]$ also developed some intuitionistic fuzzy aggregation operators, such as the intuitionistic fuzzy weighed averaging (IFWA) operator, intuitionistic fuzzy ordered weighed averaging (IFOWA) operator, and intuitionistic fuzzy hybrid averaging (IFHA) operator, $\mathrm{Xu}$ and Yager [17] developed an operator called dynamic intuitionistic fuzzy weighed averaging (DIFWA) operator and procedure to deal with the situations where all the attribute values are collected at different periods. Wei [18] proposed the dynamic intuitionistic fuzzy weighed geometric (DIFWG) operator and induced intuitionistic fuzzy ordered weighed geometric (I-IFOWG) operator [19]. Zhao et al. [20] proposed the generalized intuitionistic fuzzy weighed averaging (GIFWA) operator, generalized intuitionistic fuzzy ordered weighed averaging (GIFOWA) operator, and generalized intuitionistic fuzzy hybrid averaging (GIFHA) operator. Based on the correlation properties of the Choquet integral, $\mathrm{Xu}$ [21] and Tan and Chen [22] proposed the intuitionistic fuzzy Choquet integral operator, respectively. Xia and $\mathrm{Xu}$ [23] developed a series of intuitionistic fuzzy point aggregation operators based on the 
idea of generalized aggregation. Xu and Yager [24] developed an intuitionistic fuzzy Bonferroni mean (IFBM) and applied the weighed IFBM to MADM. Xu [25] developed a series of intuitionistic fuzzy aggregation operators, whose weighing vectors depend upon the input arguments and allow values being aggregated to support and reinforce each other. $\mathrm{Xu}$ and Wang [26] developed the intuitionistic fuzzy induced generalized aggregation operators. On the basis of the idea of the ordered weighed averaging distance (OWAD) operator $[27,28]$, Zeng and Su [29] developed an intuitionistic fuzzy ordered weighed distance (IFOWD) operator. Zeng [30] developed the intuitionistic fuzzy hybrid weighed distance measure, and presented a consensus reaching process for group decision making with intuitionistic fuzzy preference information. Yu [31] developed the intuitionistic fuzzy prioritized weighed average (IFPWA) and the intuitionistic fuzzy prioritized weighed geometric (IFPWG) operators. Yu [32] developed some new aggregation operators for intuitionisticfuzzy information are proposed, including the intuitionistic fuzzy geometric Heronian mean (IFGHM) operator and the intuitionistic fuzzy geometric weighed Heronian mean (IFGWHM) operator. Wei and Merigó [33] developed some probability intuitionistic fuzzy aggregation operators. All the above operators are based on the algebraic operational laws of IFSs for carrying the combination process and are not consistent with the limiting case of ordinary fuzzy sets [34]. Recently, Wang and Liu $[35,36]$ developed some intuitionistic fuzzy aggregation operators based on Einstein operations.

However, most of the existing aggregation operators do not take into account the relationship between the values being fused. $\mathrm{Xu}$ [37] proposed some dependent OWA operators, in which the associated weights depend on the aggregated arguments. The prominent characteristic of this dependent OWA operator is that it can relieve the influence of unfair arguments on the aggregated results. Furthermore, Xu [38] developed some dependent uncertain ordered weighed aggregation operators, including dependent uncertain ordered weighed averaging (DUOWA) operators and dependent uncertain ordered weighed geometric (DUOWG) operators, in which the associated weights only depend on the aggregated interval arguments. Wei and Zhao [39] developed a dependent uncertain linguistic ordered weighed geometric (DULOWG) operator to aggregate uncertain linguistic variable. Liu [40] developed the intuitionistic linguistic generalized dependent ordered weighed average (ILGDOWA) operator and the intuitionistic linguistic generalized dependent hybrid weighed aggregation (ILGDHWA) operator.

Nowadays, the problem of supplier selection has emerged as an active research field where numerous research papers have been published around this area within the last few years. Supplier selection plays a key role in supply chain management (SCM) and deals with evaluation, ranking, and selection of the best option from a pool of potential suppliers especially in the presence of conflicting attribute. In the literature, supplier selection has been treated as a multiple attribute decision making (MADM) and a wide range of mathematical methods have been undertaken to provide the problems with sufficient and more accurate solutions. In this paper, motivated by the idea of dependent aggregation operator proposed by $\mathrm{Xu}[37,38]$, we develop some new intuitionistic fuzzy aggregation operators, including dependent intuitionistic fuzzy ordered weighed averaging (DIFOWA) operator and dependent intuitionistic fuzzy hybrid weighed aggregation (DIFHWA) operator. Furthermore, we study some of their main desirable properties. We also apply the developed operators to multiple attribute decision making (MADM) problems concerning the supplier selection with intuitionistic fuzzy information.

\section{Preliminaries}

In this section, we introduce some basic concepts related to intuitionistic fuzzy sets. Atanassov [2-4] introduced a generalized fuzzy set called intuitionistic fuzzy set, shown as follows.

An IFS in $X$ is given by

$$
A=\left\{\left\langle x, \mu_{A}(x), v_{A}(x)\right\rangle \mid x \in X\right\}
$$

which is characterized by a membership function $\mu_{A}: X \rightarrow$ $[0,1]$ and a nonmembership function $v_{A}: X \rightarrow[0,1]$, with the condition

$$
0 \leq \mu_{A}(x)+v_{A}(x) \leq 1, \quad \forall x \in X,
$$

where the numbers $\mu_{A}(x)$ and $v_{A}(x)$ represent, respectively, the degree of membership and the degree of nonmembership of the element $x$ to the set $A$.

For each IFS $A$ in $X$, if

$$
\pi_{A}(x)=1-\mu_{A}(x)-v_{A}(x), \quad \forall x \in X,
$$

then $\pi_{A}(x)$ is called the indeterminacy degree or hesitation degree of $x$ to $A$.

For convenience, $\mathrm{Xu}$ and Yager [15] called $\alpha=\left(\mu_{\alpha}, v_{\alpha}\right)$ an intuitionistic fuzzy value (IFV), where $\mu_{\alpha} \in[0,1], v_{\alpha} \in[0,1]$, and $\mu_{\alpha}+v_{\alpha} \leq 1$. For convenience, let $\Omega$ be the set of all IFVs.

Let $\alpha=\left(\mu_{\alpha}, v_{\alpha}\right)$ be an IFV; Chen and Tan [41] introduced a score function $S$, which can be represented as follows:

$$
S(\alpha)=\mu_{\alpha}-v_{\alpha}
$$

where $S(\alpha) \in[-1,1]$.

For an IFV $\alpha=\left(\mu_{\alpha}, v_{\alpha}\right)$, it is clear that if the deviation between $\mu_{\alpha}$ and $v_{\alpha}$ gets greater, which means the value $\mu_{\alpha}$ gets bigger and the value $v_{\alpha}$ gets smaller, then the IFV $\alpha$ gets greater.

Later, Hong and Choi [42] noted that the score function alone cannot differentiate many IFVs even though they are obviously different. To make the comparison method more discriminatory, an accuracy function $H$ to evaluate the degree of accuracy of the intuitionistic fuzzy value can be represented as follows:

$$
H(\alpha)=\mu_{\alpha}+v_{\alpha}
$$

where $H(\alpha) \in[0,1]$. The larger the value of $H(\alpha)$, the higher the degree of accuracy of the degree of membership of the IFV $\alpha$. 
The score function $S$ and the accuracy function $H$ are, respectively, defined as the difference and the sum of the membership function $\mu_{A}(x)$ and the nonmembership function $v_{A}(x)$.

To rank IFVs, Xu and Yager [15] and Xu [16] developed a method for the comparison between two IFVs, which is based on the score function $S$ and the accuracy function $H$ :

(i) if $S\left(\alpha_{1}\right)<S\left(\alpha_{2}\right)$, then $\alpha_{1}<\alpha_{2}$;

(ii) if $S\left(\alpha_{1}\right)=S\left(\alpha_{2}\right)$, the

(1) if $H\left(\alpha_{1}\right)<H\left(\alpha_{2}\right)$, then $\alpha_{1}<\alpha_{2}$;

(2) if $H\left(\alpha_{1}\right)=H\left(\alpha_{2}\right)$, then $\alpha_{1}=\alpha_{2}$.

To aggregate intuitionistic preference information, $\mathrm{Xu}$ [16] defined the following operations.

Definition 1 (see [16]). Let $\alpha=\left(\mu_{\alpha}, v_{\alpha}\right)$ and $\beta=\left(\mu_{\beta}, v_{\beta}\right)$ two IFVs; then

(1) $\alpha \oplus \beta=\left(\mu_{\alpha}+\mu_{\beta}-\mu_{\alpha} \cdot \mu_{\beta}, v_{\alpha} \cdot v_{\beta}\right)$;

(2) $\alpha \otimes \beta=\left(\mu_{\alpha} \cdot \mu_{\beta}, v_{\alpha}+v_{\beta}-v_{\alpha} \cdot v_{\beta}\right)$;

(3) $\lambda \alpha=\left(1-\left(1-\mu_{\alpha}\right)^{\lambda}, v_{\alpha}^{\lambda}\right), \lambda>0$;

(4) $\alpha^{\lambda}=\left(\mu_{\alpha}^{\lambda}, 1-\left(1-v_{\alpha}\right)^{\lambda}\right), \lambda>0$.

Definition 2 (see [16]). Let $\alpha_{j}=\left(\mu_{\alpha_{j}}, v_{\alpha_{j}}\right)(j=1,2, \ldots, n)$ be a collection of IFVs and an intuitionistic fuzzy weighed averaging operator of dimension $n$ is a mapping IFWA: $\Omega^{n} \rightarrow$ $\Omega$, if

$$
\begin{aligned}
\operatorname{IFWA}_{w} & \left(\alpha_{1}, \alpha_{2}, \ldots, \alpha_{n}\right) \\
= & w_{1} \alpha_{1} \oplus w_{2} \alpha_{2} \oplus \cdots \oplus w_{n} \alpha_{n} \\
& =\left(1-\prod_{j=1}^{n}\left(1-\mu_{\alpha_{j}}\right)^{w_{j}}, \prod_{j=1}^{n}\left(v_{\alpha_{j}}\right)^{w_{j}}\right),
\end{aligned}
$$

where $w=\left(w_{1}, w_{2}, \ldots, w_{n}\right)^{T}$ is the weighing vector of $\alpha_{j}(j=$ $1,2, \ldots, n)$ such that $w_{j} \in[0,1], j=1,2, \ldots, n$ and $\sum_{j=1}^{n} w_{j}=$ 1.

The OWA operator introduced by Yager [43] is an aggregation operator that provides a parameterized family of aggregation operators between the maximum and the minimum. Since its introduction, lots of extensions of the OWA operator have been studied, such as the weighed OWA (WOWA) [44], the hybrid averaging (HA) operator [45], the ordered weighed averaging weighed averaging (OWAWA) operator [46], and the immediate weighed OWA distance (IWOWAD) operator [47]. It can be defined as follows.

Definition 3 (see [43]). An OWA operator of dimension $n$ is a mapping OWA: $R^{n} \rightarrow R$ that has an associated weighing $W$ with $w_{j} \in[0,1]$ and $\sum_{j=1}^{n} w_{j}=1$, such that

$$
\operatorname{OWA}\left(a_{1}, \ldots, a_{n}\right)=\sum_{j=1}^{n} w_{j} b_{j},
$$

where $b_{j}$ is the $j$ th largest of the $a_{i}$.
The OWA operator has been used in a wide range of applications, such as engineering, neural networks, data mining, decision making, image process, and expert systems. Consider that the OWA operator aggregates only the exact inputs having been reordered; Xu [16] extended the OWA operator to accommodate the situations where the input arguments are intuitionistic fuzzy numbers and developed the intuitionistic fuzzy ordered weighed averaging (IFOWA) operator.

Definition 4 (see [16]). Let $\alpha_{j}=\left(\mu_{\alpha_{j}}, v_{\alpha_{j}}\right)(j=1,2, \ldots, n)$ be a collection of IFVs and an intuitionistic fuzzy ordered weighed averaging operator of dimension $n$ is a mapping IFOWA: $\Omega^{n} \rightarrow \Omega$, if

$$
\begin{aligned}
\operatorname{IFOWA}_{w}\left(\alpha_{1}, \alpha_{2}, \ldots, \alpha_{n}\right) \\
=w_{1} \alpha_{\sigma(1)} \oplus w_{2} \alpha_{\sigma(2)} \oplus \cdots \oplus w_{n} \alpha_{\sigma(n)} \\
=\left(1-\prod_{j=1}^{n}\left(1-\mu_{\alpha_{\sigma(j)}}\right)^{w_{j}}, \prod_{j=1}^{n}\left(v_{\alpha_{\sigma(j)}}\right)^{\omega_{j}}\right),
\end{aligned}
$$

where $(\sigma(1), \sigma(2), \ldots, \sigma(n))$ is a permutation of $(1,2, \ldots, n)$ such that $\alpha_{\sigma(j-1)} \geq \alpha_{\sigma(j)}$ for all $j$; $w=\left(w_{1}, w_{2}, \ldots, w_{n}\right)^{T}$ is the weighing vector of IFOWA such that $w_{j} \in[0,1], j=$ $1,2, \ldots, n$, and $\sum_{j=1}^{n} w_{j}=1$.

\section{Some Dependent Intuitionistic Fuzzy Aggregation Operators}

As an interesting and important research topic in IFS theory, similarity measure between intuitionistic fuzzy set (IFS) has been receiving more and more attention in recent years. Recently, motivated by the idea of the TOPSIS of Hwang and Yoon [48], $\mathrm{Xu}$ and Yager [49] introduced an intuitionistic fuzzy similarity measure combining the distance measure as follows.

Definition 5 (see [44]). Let $\alpha_{1}=\left(\mu_{\alpha_{1}}, v_{\alpha_{1}}\right)$ and $\alpha_{2}=\left(\mu_{\alpha_{2}}, v_{\alpha_{2}}\right)$ be two IFVs and $\alpha_{2}^{c}=\left(v_{\alpha_{2}}, \mu_{\alpha_{2}}\right)$ the complement of $\alpha_{2}$; then

$$
s\left(\alpha_{1}, \alpha_{2}\right)= \begin{cases}0.5, & \alpha_{1}=\alpha_{2}=\alpha_{2}^{c} \\ \frac{d\left(\alpha_{1}, \alpha_{2}^{c}\right)}{d\left(\alpha_{1}, \alpha_{2}\right)+\left(\alpha_{1}, \alpha_{2}^{c}\right)}, & \text { otherwise }\end{cases}
$$

is called the similarity measure between $\alpha_{1}$ and $\alpha_{2}$, where

$$
d\left(\alpha_{1}, \alpha_{2}\right)=\frac{1}{2}\left(\left|\mu_{\alpha_{1}}-\mu_{\alpha_{2}}\right|+\left|v_{\alpha_{1}}-v_{\alpha_{2}}\right|+\left|\pi_{\alpha_{1}}-\pi_{\alpha_{2}}\right|\right)
$$

is the Hamming distance between $\alpha_{1}$ and $\alpha_{2}$.

Definition 6. Let $\alpha_{j}=\left(\mu_{\alpha_{j}}, v_{\alpha_{j}}\right)(j=1,2, \ldots, n)$ be a collection of IFVs; the intuitionistic fuzzy arithmetic mean is computed as

$$
\alpha=\frac{1}{n}\left(\alpha_{1} \oplus \alpha_{2} \oplus \cdots \oplus \alpha_{n}\right)=\left(1-\prod_{i=1}^{n}\left(1-\mu_{j}\right)^{1 / n}, \prod_{i=1}^{n} v_{j}^{1 / n}\right) .
$$


In real-life decision making problems, the decision making experts may have personal biases and some individuals may give unduly high or unduly low preference values to their preferred or repugnant objects. In such a case, we will assign very low weights to these false or biased opinions that is to say, the closer a preference value (argument) is to the mid one(s), the more the weight is. As a result, based on (8) and (10), we define the IFOWA weights as

$$
w_{j}=\frac{s\left(\alpha_{\sigma(j)}, \alpha\right)}{\sum_{j=1}^{n} s\left(\alpha_{\sigma(j)}, \alpha\right)} .
$$

Obviously, $w_{j} \geq 0$ and $\sum_{j=1}^{n} w_{j}=1$. In particular, if $\alpha_{i}=\alpha_{j}$ for $i, j=1,2, \ldots, n$, then by $(12)$, we have $w_{j}=(1 / n)(j=$ $1,2, \ldots, n)$.

Theorem 7. Let $\alpha_{j}=\left(\mu_{j}, v_{j}\right)(j=1,2, \ldots, n)$ be a set of IFV and $\alpha$ the arithmetic mean of these IFV $(\sigma(1), \sigma(2), \ldots, \sigma(n))$ is a permutation of $(1,2, \ldots, n)$, such that $\sigma(j-1) \geq \sigma(j)$ for all $j=1,2, \ldots, n$. If $s\left(\alpha_{\sigma(j)}, \alpha\right) \geq s\left(\alpha_{\sigma(i)}, \alpha\right)$, then $w_{j} \geq w_{i}$.

By (11), we have

$$
\begin{array}{r}
\operatorname{IFOWA}\left(\alpha_{1}, \alpha_{2}, \ldots, \alpha_{n}\right) \\
=\sum_{j=1}^{n} \frac{s\left(\alpha_{\sigma(j)}, \alpha\right)}{\sum_{j=1}^{n} s\left(\alpha_{\sigma(j)}, \alpha\right)} \alpha_{\sigma(j)}=\frac{\sum_{j=1}^{n} s\left(\alpha_{\sigma(j)}, \alpha\right) \alpha_{\sigma(j)}}{\sum_{j=1}^{n} s\left(\alpha_{\sigma(j)}, \alpha\right)} .
\end{array}
$$

Since

$$
\begin{gathered}
\sum_{j=1}^{n} s\left(\alpha_{\sigma(j)}, \alpha\right) \alpha_{\sigma(j)}=\sum_{j=1}^{n} s\left(\alpha_{j}, \alpha\right) \alpha_{j}, \\
\sum_{j=1}^{n} s\left(\alpha_{\sigma(j)}, \alpha\right)=\sum_{j=1}^{n} s\left(\alpha_{j}, \alpha\right) ;
\end{gathered}
$$

then we can replace (13) by

$$
\operatorname{IFOWA}\left(\alpha_{1}, \alpha_{2}, \ldots, \alpha_{n}\right)=\frac{\sum_{j=1}^{n} s\left(\alpha_{j}, \alpha\right) \alpha_{j}}{\sum_{j=1}^{n} s\left(\alpha_{j}, \alpha\right)} .
$$

We call (15) a dependent intuitionistic fuzzy ordered weighed averaging (DIFOWA) operator, which is a generalization of the dependent ordered weighed averaging (DOWA) operator [37]. Consider that the aggregated value of the DIFOWA operator is independent of the ordering; thus it is also a neat operator. From (15) we know that all the associated weights of the DIFOWA operator only depend on the aggregated IFVs and can relieve the influence of unfair arguments on the aggregated results by assigning low weights to those "false" and "biased" ones and thus make the aggregated results more reasonable in the practical applications.

Similar to the DOWA operator, the DIFOWA operator has the following properties.
Theorem 8 (commutativity). Let $\left(\alpha_{1}^{\prime}, \alpha_{2}^{\prime}, \ldots, \alpha_{n}^{\prime}\right)$ be any permutation of $\left(\alpha_{1}, \alpha_{2}, \ldots, \alpha_{n}\right)$; then

$$
\text { DIFOWA }\left(\alpha_{1}, \alpha_{2}, \ldots, \alpha_{n}\right)=\text { DIFOWA }\left(\alpha_{1}^{\prime}, \alpha_{2}^{\prime}, \ldots, \alpha_{n}^{\prime}\right) \text {. }
$$

Proof. Let

$$
\begin{aligned}
& \operatorname{DiFOWA}\left(\alpha_{1}, \alpha_{2}, \ldots, \alpha_{n}\right)=\frac{\sum_{j=1}^{n} s\left(\alpha_{j}, \alpha\right) \alpha_{j}}{\sum_{j=1}^{n} s\left(\alpha_{j}, \alpha\right)}, \\
& \operatorname{DIFOWA}\left(\alpha_{1}^{\prime}, \alpha_{2}^{\prime}, \ldots, \alpha_{n}^{\prime}\right)=\frac{\sum_{j=1}^{n} s\left(\alpha_{j}^{\prime}, \alpha\right) \alpha_{j}^{\prime}}{\sum_{j=1}^{n} s\left(\alpha_{j}^{\prime}, \alpha\right)} .
\end{aligned}
$$

Since $\left(\alpha_{1}^{\prime}, \alpha_{2}^{\prime}, \ldots, \alpha_{n}^{\prime}\right)$ is any permutation of $\left(\alpha_{1}, \alpha_{2}, \ldots, \alpha_{n}\right)$, we have

$$
\begin{gathered}
\sum_{j=1}^{n} s\left(\alpha_{j}, \alpha\right) \alpha_{j}=\sum_{j=1}^{n} s\left(\alpha_{j}^{\prime}, \alpha\right) \alpha_{j}^{\prime}, \\
\sum_{j=1}^{n} s\left(\alpha_{j}, \alpha\right)=\sum_{j=1}^{n} s\left(\alpha_{j}, \alpha\right) .
\end{gathered}
$$

Thus

$$
\operatorname{DIFOWA}\left(\alpha_{1}, \alpha_{2}, \ldots, \alpha_{n}\right)=\operatorname{DIFOWA}\left(\alpha_{1}^{\prime}, \alpha_{2}^{\prime}, \ldots, \alpha_{n}^{\prime}\right) \text {. }
$$

Theorem 9 (idempotency). Let $\alpha_{j}=\alpha^{*}(j=1,2, \ldots, n)$; then

$$
\text { DIFOWA }\left(\alpha_{1}, \alpha_{2}, \ldots, \alpha_{n}\right)=\alpha^{*} \text {. }
$$

Proof. Since $\alpha_{j}=\alpha^{*}$ for all $j$, we have

$$
\begin{aligned}
\operatorname{DIFOWA}\left(\alpha_{1}, \alpha_{2}, \ldots, \alpha_{n}\right) & =\frac{\sum_{j=1}^{n} s\left(\alpha_{j}, \alpha\right) \alpha_{j}}{\sum_{j=1}^{n} s\left(\alpha_{j}, \alpha\right)} \\
& =\frac{\sum_{j=1}^{n} s\left(\alpha^{*}, \alpha\right) \alpha^{*}}{\sum_{j=1}^{n} s\left(\alpha^{*}, \alpha\right)}=\alpha^{*} .
\end{aligned}
$$

This completes the proof of Theorem 9.

Theorem 10 (boundedness). The IFDOWA operator lies between the max and min operators; that is,

$$
\begin{aligned}
\min \left(\alpha_{1}, \alpha_{2}, \ldots, \alpha_{n}\right) & \leq \operatorname{DIFOWA}\left(\alpha_{1}, \alpha_{2}, \ldots, \alpha_{\mathrm{n}}\right) \\
& \leq \max \left(\alpha_{1}, \alpha_{2}, \ldots, \alpha_{n}\right) .
\end{aligned}
$$

Proof. Let

$$
a=\min \left(\alpha_{1}, \alpha_{2}, \ldots, \alpha_{n}\right), \quad b=\max \left(\alpha_{1}, \alpha_{2}, \ldots, \alpha_{n}\right) .
$$

Since $a \leq \alpha_{j} \leq b$, we have

$$
\frac{\sum_{j=1}^{n} s\left(\alpha_{j}, \alpha\right) a}{\sum_{j=1}^{n} s\left(\alpha_{j}, \alpha\right)} \leq \frac{\sum_{j=1}^{n} s\left(\alpha_{j}, \alpha\right) \alpha_{j}}{\sum_{j=1}^{n} s\left(\alpha_{j}, \alpha\right)} \leq \frac{\sum_{j=1}^{n} s\left(\alpha_{j}, \alpha\right) b}{\sum_{j=1}^{n} s\left(\alpha_{j}, \alpha\right)} .
$$


That is,

$$
a \leq \frac{\sum_{j=1}^{n} s\left(\alpha_{j}, \alpha\right) \alpha_{j}}{\sum_{j=1}^{n} s\left(\alpha_{j}, \alpha\right)} \leq b
$$

thus

$$
\begin{aligned}
\min \left(\alpha_{1}, \alpha_{2}, \ldots, \alpha_{n}\right) & \leq \operatorname{DIFOWA}\left(\alpha_{1}, \alpha_{2}, \ldots, \alpha_{n}\right) \\
& \leq \max \left(\alpha_{1}, \alpha_{2}, \ldots, \alpha_{n}\right) .
\end{aligned}
$$

The IFWA operator only considers the weight of the aggregated IFVs, and in IFDOWA operator, we assumed that all of the IFVs being aggregated were of equal importance. However, in many cases, the importance degrees should not be treated as equally important and thus need to be assigned different weights. Here, we will consider the effect on the dependent operations of having differing importance of the objects. So, in what follows, we will develop a new aggregation operator to process this case.

Definition 11. Let $\alpha_{j}=\left(\mu_{j}, v_{j}\right)(j=1,2, \ldots, n)$ be a collection of the IFV and DIFHWA: $\Omega^{n} \rightarrow \Omega$. If

$$
\begin{aligned}
\operatorname{DIFHWA}\left(\alpha_{1}, \alpha_{2}, \ldots, \alpha_{n}\right) & =\sum_{j=1}^{n} w_{j} \dot{\alpha}_{\sigma(j)} \\
& =\frac{\sum_{j=1}^{n} s\left(\alpha_{\sigma(j)}, \alpha\right) \dot{\alpha}_{\sigma(j)}}{\sum_{j=1}^{n} s\left(\alpha_{\sigma(j)}, \alpha\right)},
\end{aligned}
$$

where $\dot{\alpha}_{j}=n \omega_{j} \alpha_{j},(\sigma(1), \sigma(2), \ldots, \sigma(n))$ is a permutation of $(1,2, \ldots, n)$, such that $\dot{\alpha}_{\sigma(j-1)} \geq \dot{\alpha}_{\sigma(j)}$ for all $j=1,2, \ldots, n$ and $\omega=\left(\omega_{1}, \omega_{2}, \ldots, \omega_{n}\right)^{T}$ is the weight vector of $\alpha_{j}=$ $\left(\mu_{j}, v_{j}\right)(j=1,2, \ldots, n)$ with $\omega_{j} \in[0,1]$ and $\sum_{j=1}^{n} \omega_{j}=$ 1 ; then DIFHWA is called the dependent intuitionistic fuzzy hybrid weighed aggregation operator. In particular, if $\omega=(1 / n, 1 / n, \ldots, 1 / n)^{T}$, then DIFHWA is reduced to the DIFOWA operator.

Since

$$
\begin{gathered}
\sum_{j=1}^{n} s\left(\alpha_{\sigma(j)}, \alpha\right) \dot{\alpha}_{\sigma(j)}=\sum_{j=1}^{n} s\left(\alpha_{j}, \alpha\right) \dot{\alpha}_{j}, \\
\sum_{j=1}^{n} s\left(\alpha_{\sigma(j)}, \alpha\right)=\sum_{j=1}^{n} s\left(\alpha_{j}, \alpha\right) .
\end{gathered}
$$

So we can replace (27) by

$$
\operatorname{DIFHWA}\left(\alpha_{1}, \alpha_{2}, \ldots, \alpha_{n}\right)=\frac{\sum_{j=1}^{n} s\left(\alpha_{j}, \alpha\right) \dot{\alpha}_{j}}{\sum_{j=1}^{n} s\left(\alpha_{j}, \alpha\right)}
$$

From (29), we can see that the DIFHWA operator can not only consider the object weight but also relieve the influence of unfair arguments on the aggregated results by assigning low weights to those "false" and "biased" ones.
Theorem 12. The DIFOWA operator is a special case of the DIHHWA operator.

Proof. Let $\omega=(1 / n, 1 / n, \ldots, 1 / n)^{T}$; then $\dot{\alpha}_{j}=\alpha_{j}$ for all $j=$ $1,2, \ldots, n$, and we have

$$
\begin{aligned}
\operatorname{DIFHWA}\left(\alpha_{1}, \alpha_{2}, \ldots, \alpha_{n}\right) & =\frac{\sum_{j=1}^{n} s\left(\alpha_{j}, \alpha\right) \dot{\alpha}_{j}}{\sum_{j=1}^{n} s\left(\alpha_{j}, \alpha\right)} \\
& =\frac{\sum_{j=1}^{n} s\left(\alpha_{j}, \alpha\right) \alpha_{j}}{\sum_{j=1}^{n} s\left(\alpha_{j}, \alpha\right)} \\
& =\operatorname{DIFOWA}\left(\alpha_{1}, \alpha_{2}, \ldots, \alpha_{n}\right) .
\end{aligned}
$$

This completes the proof of Theorem 12 .

\section{An Approach to Multiple Attribute Decision Making Based on the DIFHWA Operator}

For the multiple attribute decision making problems, in which both the attribute weights and the expert weights take the form of real numbers, and the attribute preference values take the form of IFVs, we will develop an approach based on the IFWA and DIFHWA operators to multiple attribute group decision making based on intuitionistic fuzzy information processing.

Let $A=\left\{A_{1}, A_{2}, \ldots, A_{m}\right\}$ be a discrete set of alternatives, let $G=\left\{G_{1}, G_{2}, \ldots, G_{n}\right\}$ be the set of attributes, let $w=$ $\left(w_{1}, w_{2}, \ldots, w_{n}\right)^{T}$ be the weighing vector of the attribute, where $w_{j} \in[0,1], \sum_{j=1}^{n} w_{j}=1, D=\left\{D_{1}, D_{2}, \ldots, D_{t}\right\}$ be the set of decision makers, and, $\lambda=\left(\lambda_{1}, \lambda_{2}, \ldots, \lambda_{t}\right)$ be the expert weight, with $\lambda_{k} \in[0,1]$ and $\sum_{k=1}^{t} \lambda_{k}=1$. Suppose that $R^{(k)}=\left(r_{i j}^{(k)}\right)_{m \times n}(k=1,2, \ldots, t)$ is the decision matrix, where $r_{i j}^{(k)}=\left(\mu_{i j}^{(k)}, v_{i j}^{(k)}\right)$ takes the form of the IFV, given by the decision maker $D_{k} \in D$, for alternative $A_{i} \in A$ with respect to the attribute $G_{j} \in G$. The methods involve the following steps.

Step 1. Utilize the decision information given in matrix $R^{(k)}$ and the IFWA operator

$$
\begin{array}{r}
r_{i}^{(k)}=\operatorname{IFWA}_{w}\left(r_{i 1}^{(k)}, r_{i 2}^{(k)}, \ldots, r_{i n}^{(k)}\right), \\
i=1,2, \ldots, m ; k=1,2, \ldots, t
\end{array}
$$

to derive the individual overall preference value $r_{i}^{(k)}$ of the alternative $A_{i}$.

Step 2. Utilize (9)-(11) to calculate the degree of similarity $s\left(r_{i}^{(k)}, x_{i}\right)$ :

$$
s\left(r_{i}^{(k)}, x_{i}\right)= \begin{cases}0.5, & r_{i}^{(k)}=x_{i}=x_{i}^{c}, \\ \frac{d\left(r_{i}^{(k)}, x_{i}^{c}\right)}{d\left(r_{i}^{(k)}, x_{i}\right)+d\left(r_{i}^{(k)}, x_{i}^{c}\right)}, & \text { otherwise }\end{cases}
$$

where $x_{i}$ is mean of the $\left(r_{i}^{(1)}, r_{i}^{(2)}, \ldots, r_{i}^{(t)}\right)$. 
TABLE 1: Intuitionistic fuzzy decision matrix $R^{(1)}$.

\begin{tabular}{cccccc}
\hline & $G_{1}$ & $G_{2}$ & $G_{3}$ & $G_{4}$ & $G_{5}$ \\
\hline$A_{1}$ & $(0.4,0.5)$ & $(0.5,0.2)$ & $(0.6,0.2)$ & $(0.8,0.1)$ & $(0.7,0.3)$ \\
$A_{2}$ & $(0.6,0.2)$ & $(0.7,0.2)$ & $(0.3,0.4)$ & $(0.5,0.1)$ & $(0.7,0.3)$ \\
$A_{3}$ & $(0.7,0.3)$ & $(0.8,0.1)$ & $(0.5,0.5)$ & $(0.3,0.2)$ & $(0.6,0.3)$ \\
$A_{4}$ & $(0.3,0.4)$ & $(0.7,0.1)$ & $(0.6,0.1)$ & $(0.4,0.3)$ & $(0.9,0.1)$ \\
$A_{5}$ & $(0.8,0.1)$ & $(0.3,0.4)$ & $(0.4,0.5)$ & $(0.7,0.2)$ & $(0.5,0.2)$ \\
\hline
\end{tabular}

TABLE 2: Intuitionistic fuzzy decision matrix $R^{(2)}$.

\begin{tabular}{cccccc}
\hline & $G_{1}$ & $G_{2}$ & $G_{3}$ & $G_{4}$ & $G_{5}$ \\
\hline$A_{1}$ & $(0.5,0.3)$ & $(0.6,0.1)$ & $(0.7,0.3)$ & $(0.7,0.1)$ & $(0.8,0.2)$ \\
$A_{2}$ & $(0.7,0.2)$ & $(0.6,0.2)$ & $(0.4,0.4)$ & $(0.6,0.2)$ & $(0.7,0.3)$ \\
$A_{3}$ & $(0.5,0.3)$ & $(0.7,0.2)$ & $(0.6,0.3)$ & $(0.4,0.2)$ & $(0.6,0.1)$ \\
$A_{4}$ & $(0.5,0.4)$ & $(0.8,0.1)$ & $(0.4,0.2)$ & $(0.7,0.2)$ & $(0.7,0.3)$ \\
$A_{5}$ & $(0.7,0.3)$ & $(0.5,0.4)$ & $(0.6,0.3)$ & $(0.6,0.2)$ & $(0.5,0.1)$ \\
\hline
\end{tabular}

Step 3. Utilize the DIFHWA operator:

$$
\begin{aligned}
r_{i} & =\operatorname{DIFHWA}\left(r_{i}^{(1)}, r_{i}^{(2)}, \ldots, r_{i}^{(t)}\right) \\
& =\frac{\sum_{k=1}^{t} s\left(r_{i}^{(k)}, x_{i}\right)\left(t \lambda_{k} r_{i}^{(k)}\right)}{\sum_{k=1}^{t} s\left(r_{i}^{(k)}, x_{i}\right)}
\end{aligned}
$$

to derive the collective overall preference values $r_{i}(i=$ $1,2, \ldots, m)$ of the alternative $A_{i}$.

Step 4. Rank all the alternatives $A_{i}(i=1,2, \ldots, m)$ and select the best one(s) in accordance with the collective overall preference values $r_{i}(i=1,2, \ldots, m)$.

Step 5. End.

\section{Illustrative Example}

In this section, we discuss a problem concerning a manufacturing company, searching the best global supplier for one of its most critical parts used in assembling process (adapted from Chan and Kumar [50]). The attributes which are considered here in selection of five potential global suppliers $A_{i}(i=1,2,3,4,5)$ are (1) $G_{1}$ : overall cost of the product; (2) $G_{2}$ : quality of the product; (3) $G_{3}$ : service performance of supplier; (4) $G_{4}$ : supplier's profile; and (5) $G_{5}$ : risk factor. The five alternatives are to be evaluated using IFVs by four decision makers (whose weighing vector $\left.\lambda=(0.3,0.2,0.3,0.2)^{T}\right)$ under the above five attributes (whose weighing vector $w=(0.2,0.15,0.2,0.3,0.15)^{T}$ ), and construct, respectively, the intuitionistic fuzzy decision matrices as listed in Tables 1, 2, 3, and 4 .

To get the best alternative(s), the following steps are involved.
TABLE 3: Intuitionistic fuzzy decision matrix $R^{(3)}$.

\begin{tabular}{cccccc}
\hline & $G_{1}$ & $G_{2}$ & $G_{3}$ & $G_{4}$ & $G_{5}$ \\
\hline$A_{1}$ & $(0.6,0.3)$ & $(0.5,0.2)$ & $(0.6,0.4)$ & $(0.8,0.1)$ & $(0.7,0.3)$ \\
$A_{2}$ & $(0.8,0.2)$ & $(0.5,0.3)$ & $(0.6,0.4)$ & $(0.5,0.2)$ & $(0.6,0.3)$ \\
$A_{3}$ & $(0.6,0.1)$ & $(0.8,0.2)$ & $(0.7,0.3)$ & $(0.4,0.2)$ & $(0.8,0.1)$ \\
$A_{4}$ & $(0.6,0.3)$ & $(0.6,0.1)$ & $(0.5,0.4)$ & $(0.9,0.1)$ & $(0.5,0.2)$ \\
$A_{5}$ & $(0.8,0.1)$ & $(0.6,0.2)$ & $(0.7,0.3)$ & $(0.5,0.2)$ & $(0.7,0.1)$ \\
\hline
\end{tabular}

TABLE 4: Intuitionistic fuzzy decision matrix $R^{(4)}$.

\begin{tabular}{cccccc}
\hline & $G_{1}$ & $G_{2}$ & $G_{3}$ & $G_{4}$ & $G_{5}$ \\
\hline$A_{1}$ & $(0.3,0.4)$ & $(0.9,0.1)$ & $(0.8,0.1)$ & $(0.5,0.5)$ & $(0.4,0.6)$ \\
$A_{2}$ & $(0.7,0.1)$ & $(0.7,0.3)$ & $(0.4,0.2)$ & $(0.8,0.2)$ & $(0.3,0.1)$ \\
$A_{3}$ & $(0.4,0.1)$ & $(0.5,0.2)$ & $(0.8,0.1)$ & $(0.6,0.2)$ & $(0.6,0.3)$ \\
$A_{4}$ & $(0.8,0.2)$ & $(0.5,0.1)$ & $(0.6,0.4)$ & $(0.7,0.2)$ & $(0.7,0.2)$ \\
$A_{5}$ & $(0.6,0.1)$ & $(0.8,0.2)$ & $(0.7,0.2)$ & $(0.6,0.3)$ & $(0.8,0.1)$ \\
\hline
\end{tabular}

(1) Calculate the comprehensive evaluation values $r_{i}^{(k)}$ :

$r_{1}^{(1)}=(0.651,0.207), \quad r_{2}^{(1)}=(0.483,0.187)$,

$r_{3}^{(1)}=(0.579,0.250), \quad r_{4}^{(1)}=(0.607,0.183)$,

$r_{5}^{(1)}=(0.610,0.232), \quad r_{1}^{(2)}=(0.674,0.172)$,

$r_{2}^{(2)}=(0.608,0.244), \quad r_{3}^{(2)}=(0.548,0.212)$,

$r_{4}^{(2)}=(0.641,0.220), \quad r_{5}^{(2)}=(0.596,0.235)$,

$r_{1}^{(3)}=(0.678,0.215), \quad r_{2}^{(3)}=(0.631,0.244)$,

$r_{3}^{(3)}=(0.654,0.170), \quad r_{4}^{(3)}=(0.727,0.182)$,

$r_{5}^{(3)}=(0.663,0.170), \quad r_{1}^{(4)}=(0.641,0.280)$,

$r_{2}^{(4)}=(0.653,0.167), \quad r_{3}^{(4)}=(0.610,0.161)$,

$r_{4}^{(4)}=(0.684,0.207), \quad r_{5}^{(4)}=(0.693,0.177)$.

(2) Calculate the degree of similarity $s\left(r_{i}^{(k)}, x_{i}\right)$ :

$$
\begin{array}{lc}
s\left(r_{1}^{(1)}, x_{1}\right)=0.961, & s\left(r_{1}^{(2)}, x_{1}\right)=0.919, \\
s\left(r_{1}^{(3)}, x_{1}\right)=0.965, & s\left(r_{1}^{(4)}, x_{1}\right)=0.868, \\
s\left(r_{2}^{(1)}, x_{2}\right)=0.750, & s\left(r_{2}^{(2)}, x_{2}\right)=0.899, \\
s\left(r_{2}^{(3)}, x_{2}\right)=0.862, & s\left(r_{2}^{(4)}, x_{2}\right)=0.890, \\
s\left(r_{3}^{(1)}, x_{3}\right)=0.866, & s\left(r_{3}^{(2)}, x_{3}\right)=0.943, \\
s\left(r_{3}^{(3)}, x_{3}\right)=0.900, & s\left(r_{3}^{(4)}, x_{3}\right)=0.949, \\
s\left(r_{4}^{(1)}, x_{4}\right)=0.928, & s\left(r_{4}^{(2)}, x_{4}\right)=0.898
\end{array}
$$




$$
\begin{array}{ll}
s\left(r_{4}^{(3)}, x_{4}\right)=0.938, & s\left(r_{4}^{(4)}, x_{4}\right)=0.906, \\
s\left(r_{5}^{(1)}, x_{5}\right)=0.962, & s\left(r_{5}^{(2)}, x_{5}\right)=0.919, \\
s\left(r_{5}^{(3)}, x_{5}\right)=0.965, & s\left(r_{5}^{(4)}, x_{5}\right)=0.868 .
\end{array}
$$

(3) Calculate the comprehensive evaluation value of each alternative:

$$
\begin{gathered}
r_{1}=(0.665,0.211), \quad r_{2}=(0.592,0.213), \\
r_{3}=(0.603,0.197), \quad r_{4}=(0.667,0.197), \\
r_{5}=(0.643,0.200) .
\end{gathered}
$$

(4) Calculate the score function $S\left(r_{i}\right)$ and $\operatorname{rank} r_{i}(i=$ $1,2, \ldots, 5)$.

Since

$$
\begin{gathered}
S\left(r_{1}\right)=0.454, \quad S\left(r_{2}\right)=0.379 \\
S\left(r_{3}\right)=0.406, \quad S\left(r_{4}\right)=0.467, \\
S\left(r_{5}\right)=0.443 .
\end{gathered}
$$

Then

$$
S\left(r_{4}\right)>S\left(r_{1}\right)>S\left(r_{5}\right)>S\left(r_{3}\right)>S\left(r_{2}\right) .
$$

(5) Rank all the alternatives.

According to the ranking of score function $S\left(r_{i}\right)$, the ranking is

$$
A_{4}>A_{1}>A_{5}>A_{3}>A_{2} .
$$

Thus the best alternative is $A_{4}$.

\section{Conclusion}

In this paper, we have investigated the multiple attribute decision making (MADM) problems in which both the attribute weights and the expert weights take the form of real numbers and attribute values take the form of intuitionistic fuzzy information. Motivated by the ideal of dependent aggregation operator, we develop two dependent intuitionistic fuzzy aggregation operators: the dependent intuitionistic fuzzy ordered weighed averaging (DIFOWA) operator and the dependent intuitionistic fuzzy hybrid weighed aggregation (DIFHWA) operator, in which the associated weights only depend on the aggregated intuitionistic fuzzy numbers. Furthermore, some desirable properties of the DIFOWA operator, such as commutativity and idempotency, are studied. Based on the DIFHWA operator, an approach to multiple attribute group decision making with intuitionistic fuzzy information is proposed. Because the associated weights only depend on the aggregated input arguments, the method can relieve the influence of unfair input arguments on the aggregated results by assigning low weights to those "false" and "biased" ones. Finally, an illustrative example concerning the supplier selection is given to verify the developed approach. In the future, we will continue working in the extension and application of the developed operators to other domains.

\section{Conflict of Interests}

The authors declare that there is no conflict of interests regarding the publication of this paper.

\section{Acknowledgments}

This paper is supported by the Statistical Scientific Key Research Project of China (no. 2013363), the National Funds of Social Science of China (nos. 12ATJ001, 12\&ZD211), the Key Research Center of Philosophy and Social Science of Zhejiang Province-Modern Port Service Industry and Creative Culture Research Center, Zhejiang Provincial Key Research Base for Humanities and Social Science Research (Statistics), Projects in Science and Technique of Ningbo Municipal (no. 2012B82003), Ningbo Soft Science Fund (no. 2011A1012), Ningbo Natural Science Foundation (no. 2011A610106), Zhejiang new generation mobile Internet client innovation team (no. 2012R10009-07), Projects in Association with Social Sciences Research of Zhejiang (no. 2013B069), Soft Science Key Project in Zhejiang (no. 2012C25099), Ningbo Natural Science Foundation (no. 2013A610286), the MOE Project of Key Research Institute of Humanities and Social Sciences in Universities (no. 13JJD910002), and the key research project of Zhejiang Wanli University.

\section{References}

[1] L. A. Zadeh, "Fuzzy sets," Information and Computation, vol. 8, pp. 338-353, 1965.

[2] K. T. Atanassov, "Intuitionistic fuzzy sets," Fuzzy Sets and Systems, vol. 20, no. 1, pp. 87-96, 1986.

[3] K. T. Atanassov, "More on intuitionistic fuzzy sets," Fuzzy Sets and Systems, vol. 33, no. 1, pp. 37-45, 1989.

[4] K. T. Atanassov, "New operations defined over the intuitionistic fuzzy sets," Fuzzy Sets and Systems, vol. 61, no. 2, pp. 137-142, 1994.

[5] H. Bustince and P. Burillo, "Vague sets are intuitionistic fuzzy sets," Fuzzy Sets and Systems, vol. 79, no. 3, pp. 403-405, 1996.

[6] W. L. Gau and D. J. Buehrer, "Vague sets," IEEE Transactions on Systems, Man and Cybernetics, vol. 23, no. 2, pp. 610-614, 1993.

[7] K. T. Atanassov, Intuitionistic Fuzzy Sets: Theory and Applications, vol. 35, Physica, Heidelberg, Germany, 1999.

[8] A. I. Ban, Intuitionistic Fuzzy Measures: Theory and Applications, Nova Science Publishers, New York, NY, USA, 2006.

[9] G. J. Klir, Uncertainty and Information: Foundations of Generalized Information Theory, Wiley-Interscience, Hoboken, NJ, USA, 2006.

[10] D. F. Li, "Extension of the LINMAP for multiattribute decision making under Atanassov's intuitionistic fuzzy environment," Fuzzy Optimization and Decision Making, vol. 7, no. 1, pp. 1734, 2008.

[11] S. Khaleie and M. Fasanghari, "An intuitionistic fuzzy group decision making method using entropy and association coefficient," Soft Computing, vol. 16, pp. 1197-1211, 2012.

[12] S. Z. Zeng, W. H. Su, and L. R. Sun, "A method based on similarity measures for interactive group decision-making with 
intuitionistic fuzzy preference relations," Applied Mathematical Modelling, vol. 37, pp. 6909-6917, 2013.

[13] Y. Jiang, Z. S. Xu, and X. H. Yu, "Compatibility measures and consensus models for group decision making with intuitionistic multiplicative preference relations," Applied Soft Computing, vol. 13, pp. 2075-2086, 2013.

[14] Z. S. Xu, "Intuitionistic fuzzy multi-attribute decision making: an interactive method," IEEE Transcations on Fuzzy Systems, vol. 20, pp. 514-525, 2012.

[15] Z. Xu and R. R. Yager, "Some geometric aggregation operators based on intuitionistic fuzzy sets," International Journal of General Systems, vol. 35, no. 4, pp. 417-433, 2006.

[16] Z. Xu, "Intuitionistic fuzzy aggregation operators," IEEE Transactions on Fuzzy Systems, vol. 15, no. 6, pp. 1179-1187, 2007.

[17] Z. Xu and R. R. Yager, "Dynamic intuitionistic fuzzy multiattribute decison making," International Journal of Approximate Reasoning, vol. 48, no. 1, pp. 246-262, 2008.

[18] G. W. Wei, "Some geometric aggregation functions and their application to dynamic multiple attribute decision making in the intuitionistic fuzzy setting," International Journal of Uncertainty, Fuzziness and Knowledge-Based Systems, vol. 17, no. 2, pp. 179-196, 2009.

[19] G. Wei, "Some induced geometric aggregation operators with intuitionistic fuzzy information and their application to group decision making," Applied Soft Computing Journal, vol. 10, no. 2, pp. 423-431, 2010.

[20] H. Zhao, Z. Xu, M. Ni, and S. Liu, "Generalized aggregation operators for intuitionistic fuzzy sets," International Journal of Intelligent Systems, vol. 25, no. 1, pp. 1-30, 2010.

[21] Z. Xu, "Choquet integrals of weighted intuitionistic fuzzy information," Information Sciences, vol. 180, no. 5, pp. 726-736, 2010.

[22] C. Tan and X. Chen, "Intuitionistic fuzzy Choquet integral operator for multi-criteria decision making," Expert Systems with Applications, vol. 37, no. 1, pp. 149-157, 2010.

[23] M. M. Xia and Z. S. Xu, "Generalized point operators for aggregating intuitionistic fuzzy information," International Journal of Intelligent Systems, vol. 25, pp. 1061-1080, 2010.

[24] Z. Xu and R. R. Yager, "Intuitionistic fuzzy bonferroni means," IEEE Transactions on Systems, Man, and Cybernetics B, vol. 41, no. 2, pp. 568-578, 2011.

[25] Z. Xu, "Approaches to multiple attribute group decision making based on intuitionistic fuzzy power aggregation operators," Knowledge-Based Systems, vol. 24, no. 6, pp. 749-760, 2011.

[26] Y. Xu and H. Wang, "The induced generalized aggregation operators for intuitionistic fuzzy sets and their application in group decision making," Applied Soft Computing Journal, vol. 12, no. 3, pp. 1168-1179, 2012.

[27] J. M. Merigó and A. M. Gil-Lafuente, "New decision-making techniques and their application in the selection of financial products," Information Sciences, vol. 180, no. 11, pp. 2085-2094, 2010.

[28] Z. Xu and J. Chen, "Ordered weighted distance measure," Journal of Systems Science and Systems Engineering, vol. 17, no. 4, pp. 432-445, 2008.

[29] S. Zeng and W. Su, "Intuitionistic fuzzy ordered weighted distance operator," Knowledge-Based Systems, vol. 24, no. 8, pp. 1224-1232, 2011.
[30] S. Zeng, "Some intuitionistic fuzzy weighted distance measures and their application to group decision making," Group Decision and Negotiation, vol. 22, no. 2, pp. 281-298, 2013.

[31] D. J. Yu, "Intuitionistic fuzzy prioritized operators and their application in multi-criteria group decision making," Technological and Economic Development of Economy, vol. 19, pp. 1-21, 2013.

[32] D. J. Yu, "Intuitionistic fuzzy geometric Heronian mean aggregation operators," Applied Soft Computing, vol. 13, pp. 12351246, 2013.

[33] G. W. Wei and J. M. Merigó, "Methods for strategic decisionmaking problems with immediate probabilities in intuitionistic fuzzy setting," Scientia Iranica E, vol. 19, pp. 1936-1946, 2012.

[34] G. Beliakov, H. Bustince, D. P. Goswami, U. K. Mukherjee, and N. R. Pal, "On averaging operators for Atanassov's intuitionistic fuzzy sets," Information Sciences, vol. 181, no. 6, pp. 1116-1124, 2011.

[35] W. Wang and X. Liu, "Intuitionistic fuzzy geometric aggregation operators based on einstein operations," International Journal of Intelligent Systems, vol. 26, no. 11, pp. 1049-1075, 2011.

[36] W. Z. Wang and X. W. Liu, "Intuitionistic fuzzy information aggregation using Einstein Operations," IEEE Transactions on Fuzzy Systems, vol. 20, pp. 923-938, 2012.

[37] Z. Xu, "Dependent OWA operators," in Modeling Decisions for Artificial Intelligence, vol. 3885 of Lecture Notes in Computer Science, pp. 172-178, 2006.

[38] Z. Xu, "Dependent uncertain ordered weighted aggregation operators," Information Fusion, vol. 9, no. 2, pp. 310-316, 2008.

[39] G. Wei and X. Zhao, "Some dependent aggregation operators with 2-tuple linguistic information and their application to multiple attribute group decision making," Expert Systems with Applications, vol. 39, no. 5, pp. 5881-5886, 2012.

[40] P. Liu, "Some generalized dependent aggregation operators with intuitionistic linguistic numbers and their application to group decision making," Journal of Computer and System Sciences, vol. 79, no. 1, pp. 131-143, 2013.

[41] S. M. Chen and J. M. Tan, "Handling multicriteria fuzzy decision-making problems based on vague set theory," Fuzzy Sets and Systems, vol. 67, no. 2, pp. 163-172, 1994.

[42] D. H. Hong and C. H. Choi, "Multicriteria fuzzy decisionmaking problems based on vague set theory," Fuzzy Sets and Systems, vol. 114, no. 1, pp. 103-113, 2000.

[43] R. R. Yager, "On ordered weighted averaging aggregation operators in multicriteria decisionmaking," IEEE Transactions on Systems, Man, and Cybernetics, vol. 18, no. 1, pp. 183-190, 1988.

[44] V. Torra, “The weighted OWA operator," International Journal of Intelligent Systems, vol. 12, no. 2, pp. 153-166, 1997.

[45] Z. S. Xu and Q. L. Da, "An Overview of Operators for Aggregating Information," International Journal of Intelligent Systems, vol. 18, no. 9, pp. 953-969, 2003.

[46] J. M. Merigó, "A unified model between the weighted average and the induced OWA operator," Expert Systems with Applications, vol. 38, no. 9, pp. 11560-11572, 2011.

[47] J. M. Merigó and A. M. Gil-Lafuente, "Decision-making techniques with similarity measures and OWA operators," Statistics and Operations Research Transactions, vol. 36, no. 1, pp. 81-101, 2012.

[48] C. L. Hwang and K. Yoon, Multiple Attribute Decision Making, vol. 186, Springer, Berlin, Germany, 1981. 
[49] Z. Xu and R. R. Yager, "Intuitionistic and interval-valued intuitionistic fuzzy preference relations and their measures of similarity for the evaluation of agreement within a group," Fuzzy Optimization and Decision Making, vol. 8, no. 2, pp. 123-139, 2009.

[50] F. T. S. Chan and N. Kumar, "Global supplier development considering risk factors using fuzzy extended AHP-based approach," Omega, vol. 35, no. 4, pp. 417-431, 2007. 


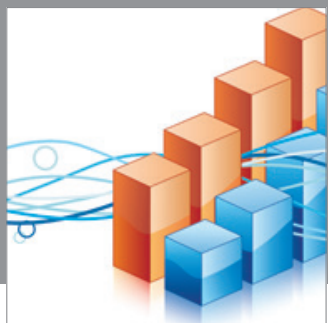

Advances in

Operations Research

mansans

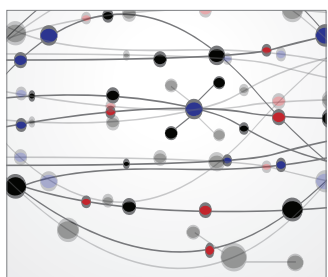

The Scientific World Journal
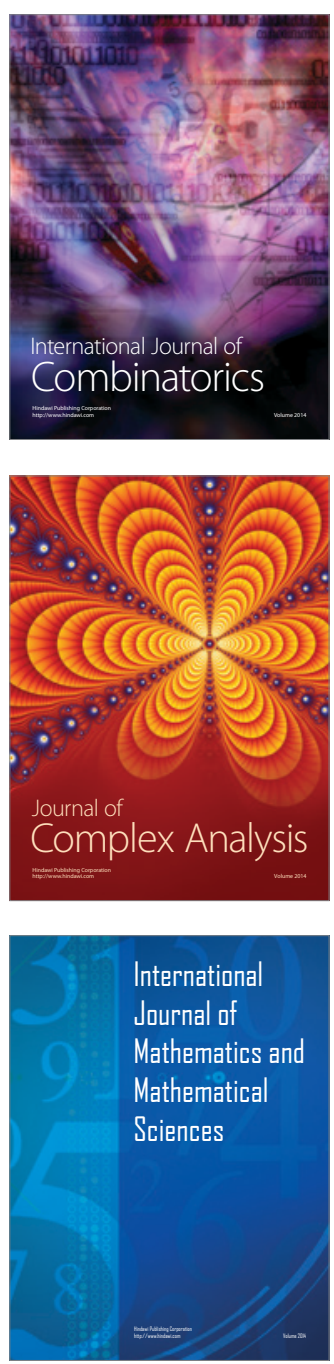
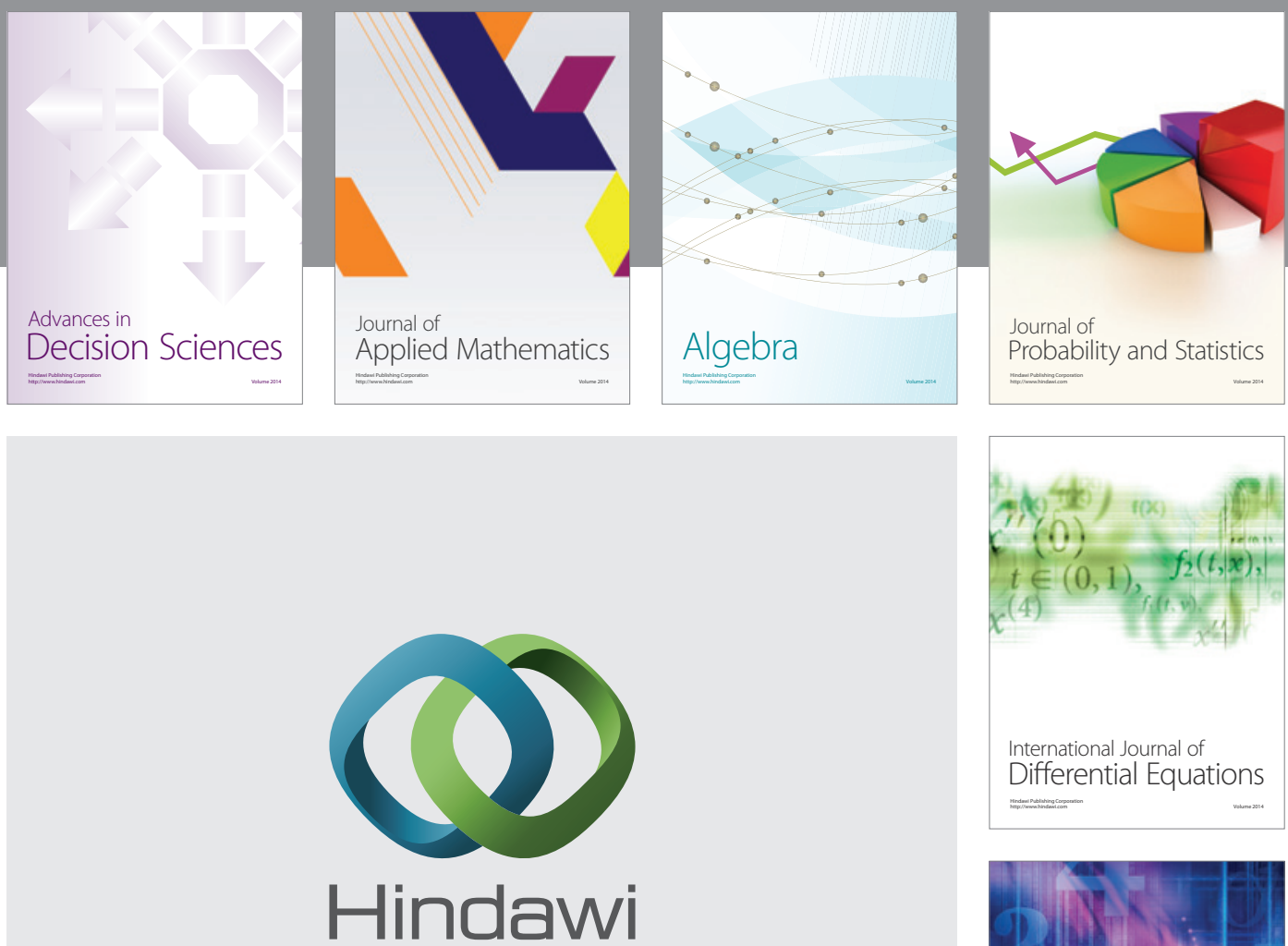

Submit your manuscripts at http://www.hindawi.com
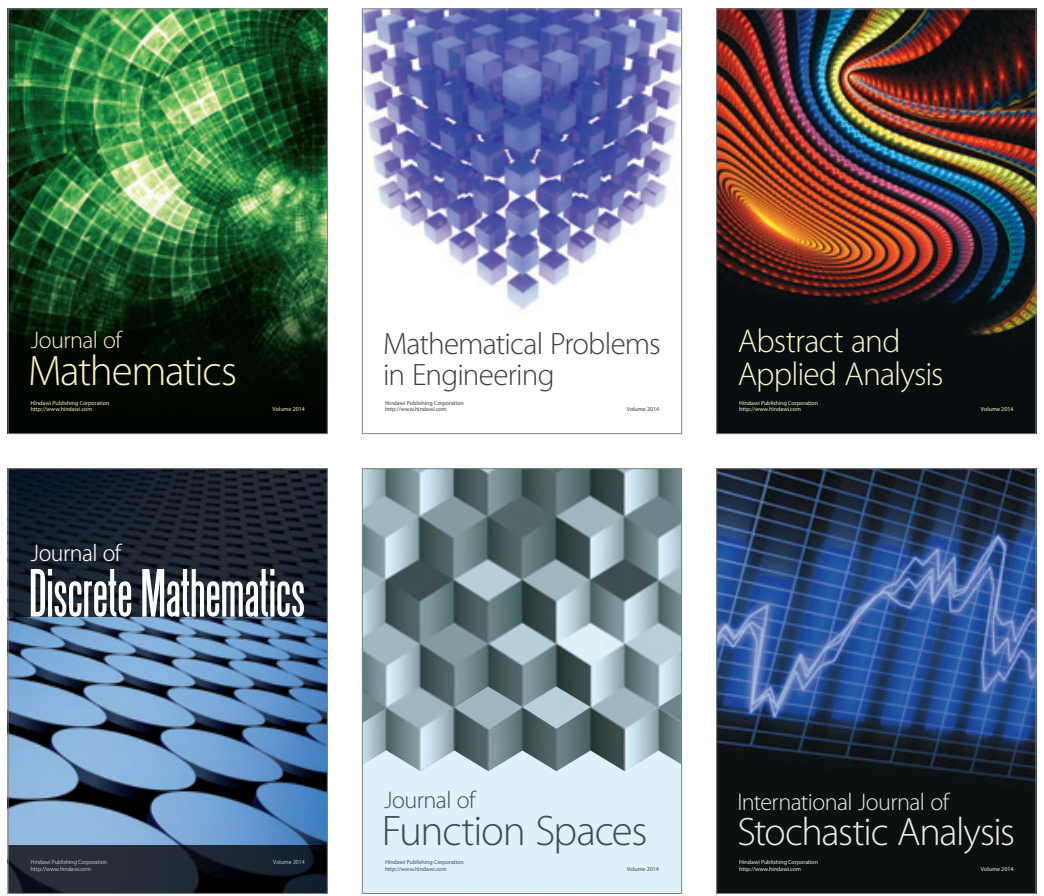

Journal of

Function Spaces

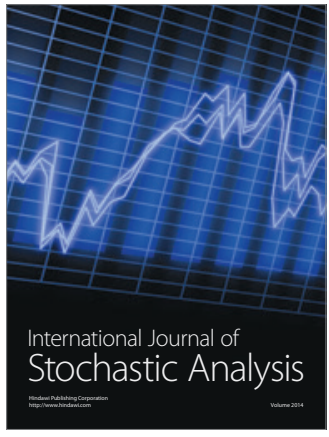

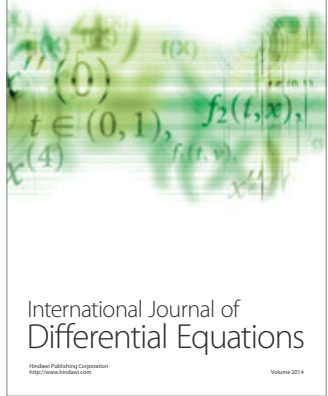
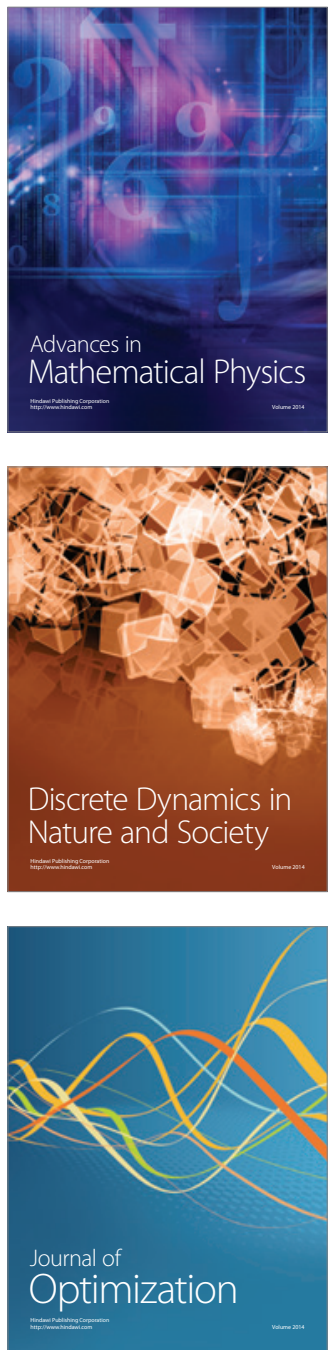